\title{
Oxidants-Antioxidants Profile in the Breast Cancer Cell Line MCF-7
}

\author{
Isnaini Isnaini ${ }^{1 *}$, Nur Permatasari ${ }^{2}$, Karyono Mintaroem ${ }^{3}$, Bunga Prihardina ${ }^{4}$, \\ M Aris Widodo ${ }^{2}$
}

\begin{abstract}
Reactive oxygen species (ROS) have various biological effects and they are non-linear in characteristic. In high oxidative stress, they may cause cytotoxicity, inhibit cell proliferation, and induce cell death in the form of apoptosis/necrosis; while in low or medium oxidative stress, ROS may cause DNA damage, cell mutation, inflammation, cell proliferation, and eventually they may induce carcinogenesis. Antioxidants are compounds with the ability to reduce ROS. Cell line MCF-7 is one of the breast cancer cell lines that is known to have small amount of antioxidant MnSOD compared to the other cell lines. Low antioxidant MnSOD level in breast cancer cell line MCF-7 leads to low concentration of hydrogen peroxide, because antioxidant MnSOD will convert radical superoxide to hydrogen peroxide. The aim of this research was to analyze oxidants and antioxidants profile in breast cancer cell line MCF-7 and their relationship with cell number. Observations were conducted for 5 days. The cell number was counted with tryphan blue method and haematometer. The concentration of radical superoxide was measured with DHE staining using LSCM tipe Olympus Fluoview FV 1000-Ver 1.7. MnSOD activity, hydrogen peroxide concentration, and catalase activity were measured with ELISA. The results showed that the longer of observation, the greater concentration of oxidants and MnSOD activity, but there was no change in catalase activity. Conclusion the increase in cancer cells number is influenced by radical superoxide.
\end{abstract}

Keywords: Oxidant- antioxidant- MCF-7- breast cancer

Asian Pac J Cancer Prev, 19 (11), 3175-3178

\section{Introduction}

Cancer cells show an increase in reactive oxygen species (ROS), due to the oncogenic stimulation, increased metabolic activity and mitochondrial damage. Mitochondrial respiratory chain is the main source of ROS production in cells. The ROS produced by cancer cells cause increased stress (Moloney and Cotter, 2017).

ROS have various biological effects and they are not linear in characteristic. In high oxidative stress, they may cause cytotoxicity, inhibit cell proliferation, and induce cell death in the form of apoptosis/necrosis; while in low or medium oxidative stress, ROS may cause DNA damage, cell mutation, inflammation, cell proliferation, and eventually they may induce carcinogenesis. Therefore, ROS are classified as endogenous carcinogen that induced cell mutation (Fang et al., 2009).

Antioxidants are compounds with the ability to reduce ROS, and classified into endogenous (originate from the inside) and exogenous antioxidants (originate from the outside). Primary endogenous antioxidants are superoxide dismutase (SOD), catalase (CAT) and glutathione peroxidase, while exogenous antioxidants are vitamin C, E, polyphenols like quercetin, kaempferol, and anthocyanin (Chio and Tuveson, 2017; Atala et al., 2017).

Endogenous antioxidant enzymes are very important for regulation of oxidative stress in the cells. One of the main cellular antioxidants is Manganese Superoxide Dismutase (MnSOD), which is one of the SOD enzymes. MnSOD changes radical superoxide $\left(\mathrm{O}_{2}^{-}\right)$to hydrogen peroxide $\left(\mathrm{H}_{2} \mathrm{O}_{2}\right)$, which in turn is changed by CAT into water. Antioxidant enzyme is the antagonist for the initiation and promotion of carcinogenesis process. The level of antioxidants decreases in many types of cancer. The common antioxidant which shows a decreased level is MnSOD (Mates and Sanchez-Jimenez, 2000). One of human breast cancer cell lines that has a decreased level of MnSOD is MCF-7 (Michigan Cancer Foundation - 7). The CAT in breast cancer cell line has high expression and activity (Kattan et al., 2008). The oxidants and antioxidants profile in MCF-7 cell line and the association with the number of cells and duration of observation were not known. This study aimed to analyze oxidants and antioxidants profile in breast cancer cell line MCF-7 and their relationship with cell number. Calculation of cell counts is useful to determine the speed between cell

${ }^{1}$ Departement of Pharmacology, Faculty of Medicine, Lambung Mangkurat University, Banjarmasin, South Kalimantan, ${ }^{2}$ Departement of Pharmacology, ${ }^{3}$ Departement Pathology, ${ }^{4}$ Biomedical Central Laboratory, Faculty of Medicine, Brawijaya University, Malang, East Java, Indonesia.*For Correspondence: isna_yusuf@yahoo.co.id 
proliferation and cell apoptosis, if the increase in the number of cells is large then cell proliferation is greater when compared to cell apoptosis.

\section{Materials and Methods}

\section{MCF-7cell culture}

The MCF-7 ATCC cell line was obtained from the Central Laboratory Natural Sciences, Brawijaya University, Malang. This research was conducted in the LSIH Brawijaya University and Biomedics Laboratory, Faculty of Medicine, Brawijaya University. The MCF-7 cells were grown in RPMI 1640 with $1 \%(\mathrm{v} / \mathrm{v})$ penicillin-streptomicin, $10 \%(\mathrm{v} / \mathrm{v})$ fetal bovine serum, incubated at $37^{\circ} \mathrm{C}$ and $5 \% \mathrm{CO}_{2}$. The cells were seeded into $1 \times 10^{4}$ cell/well. The cells were harvested at 24,48 , 72,96 and 120 hours after seeding.

\section{MCF-7 Cell counting}

Calculation of the number of cells using a hemacytometer and staining trypan blue. Living cells with intact membranes are able to exclude trypan blue so that living cells are colorless. Cells that have damaged membranes will take color and the cell will turn blue.

\section{Measurement of radical superoxides}

The MCF-7 cells were washed twice with PBS. They were suspended with $0.2 \mathrm{~mL}$ PBS of DHE at a final concentration of $10 \mu \mathrm{M}$ and incubated at $37^{\circ} \mathrm{C}$ for $20 \mathrm{~min}$. Then the cells were washed again twice with PBS. The concentration of radical superoxides was measured by LSCM type Olympus Fluoview FV 1000-Ver 1.7.

\section{Measurements of $\mathrm{H}_{2} \mathrm{O}_{2}$}

The measurement was conducted using the Hydrogen Peroxide Assay Kit $\left(\right.$ Biovision $\left.^{\circledR}\right)$. The concentration of hydrogen peroxide was measured on the cell medium. Absorbance was measured at $570 \mathrm{~nm}$ using ELISA

\section{Measurement of MnSOD activity}

The measurement was conducted using the Superoxide Dismutase Assay Kit $\left(\right.$ Cayman $\left.^{\circledR}\right)$. The cell culture was harvested by scraping. The absorbance was read at the wavelength of 440 - $460 \mathrm{~nm}$ with ELISA.

\section{Measurement of CAT activity}

The measurement of CAT activity was conducted using Catalase Activity Colorimetric Assay Kit (Biovision ${ }^{\circledR}$ ). The CAT activity was determined by measuring a reduced absorbance of $\mathrm{H}_{2} \mathrm{O}_{2}$ at $570 \mathrm{~nm}$. Absorbance was measured at $570 \mathrm{~nm}$ using an ELISA.

\section{Statistical analysis}

In this study, statistical analysis will be carried out using the Pearson correlation test.

\section{Results}

This study is useful to determine the profile of cell growth, radical superoxide concentration, MnSOD activity, hydrogen peroxide concentration and catalase
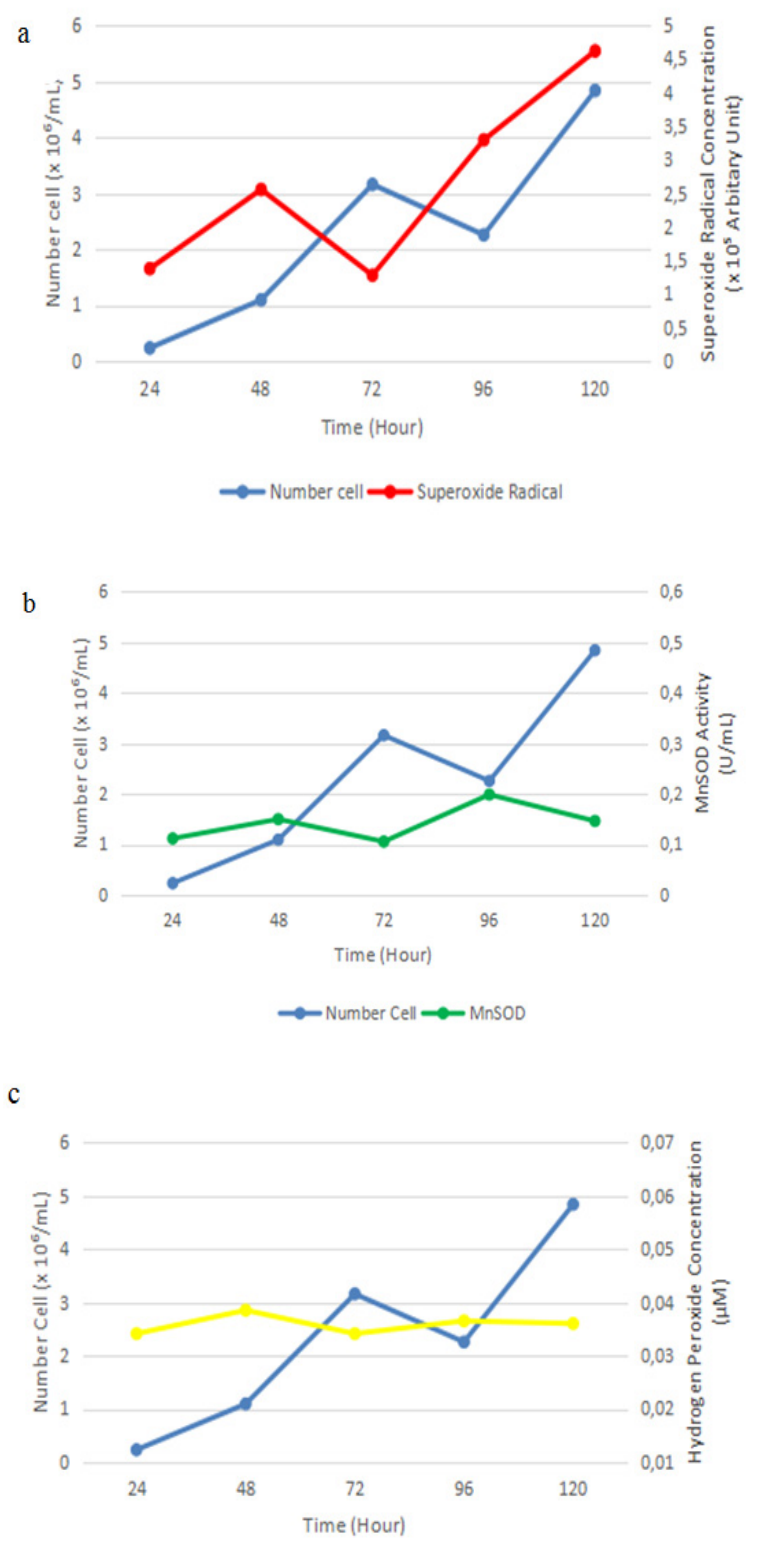

$\leadsto$ Number Cell $\longrightarrow$ Hydrogen Per oxide

d

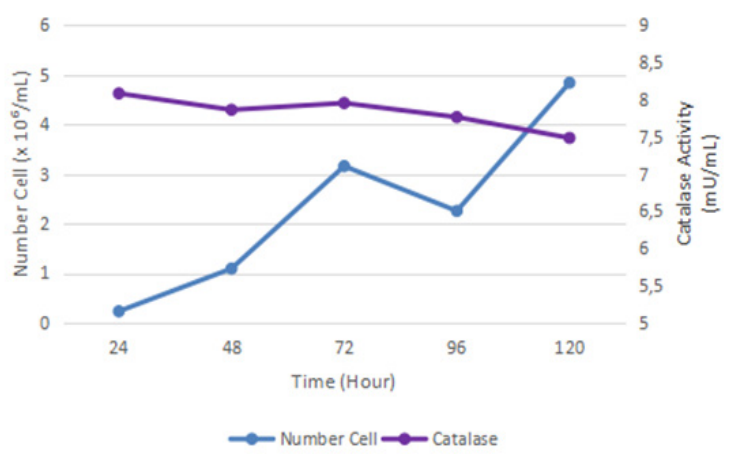

Figure 1. Cell Number MCF-7 after Incubation 24, 48, 72,96 and 120 hour. Cell number count with tryphan blue and haematometer, radical superoxide concentration determine with fluorescence DHE staining and using LSCM tipe Olympus Fluoview FV 1000-Ver 1.7., MnSOD activity, hydrogen peroxide and catalase activity determine with ELISA. (a) Cell number and radical superoxide, (b) Cell number and MnSOD activity, (c) Cell number and Hydrogen peroxide, (d) Cell number and catalase activity (replication three times) 

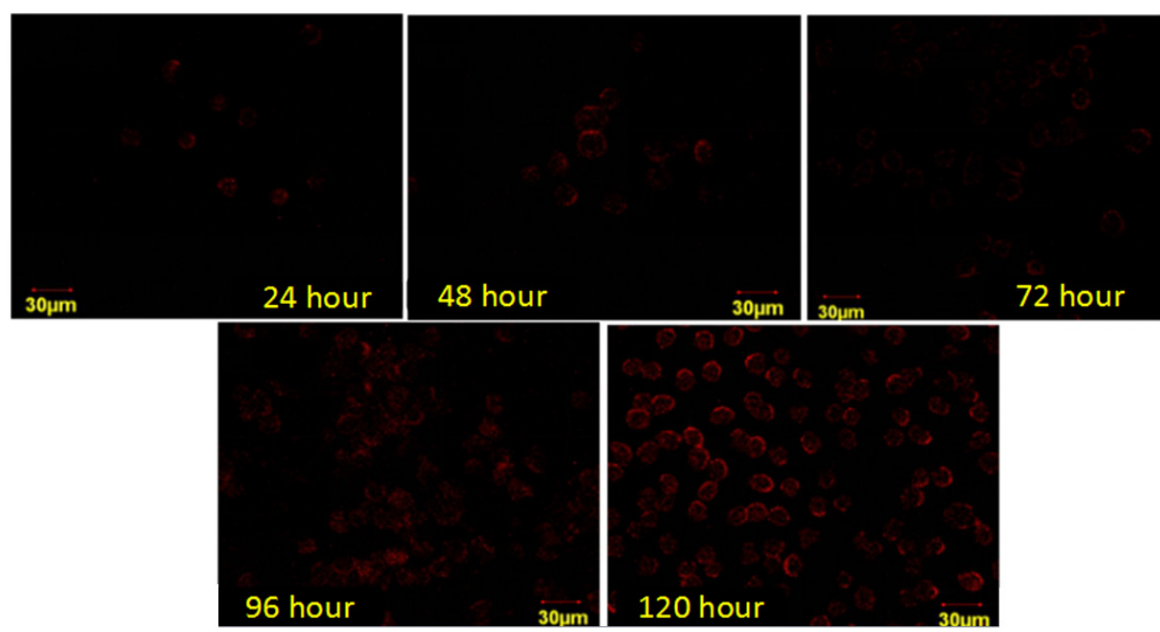

Figure 2. Radical Superoxide of Cell Line MCF-7 with Fluorescence DHE Staining

activity. The results showed that the profile of cell numbers was different from the profile of radical superoxide concentration. In the number of cells there was a decrease at 96 hours while in the profile of radical superoxide concentration there was a decrease at 72 hours. The highest concentration of radical superoxides at 120 hours with a value $\left(4.6 \times 10^{5}\right) \pm\left(1.436 \times 10^{5}\right)$ arbitary unit (Figure 1a and Figure 2). Likewise with the activity profile of MnSOD, hydrogen peroxide. MnSOD activity only ranged from $0.106 \pm 0.041 \mathrm{U} / \mathrm{ml}$ to $0.198 \pm 0.024 \mathrm{U} / \mathrm{ml}$ (Figure 1b). The hydrogen peroxide concentration ranged from $0.034 \pm 0.003 \mu \mathrm{M}$ to $0.039 \pm 0.010 \mu \mathrm{M}$ (Figure 1c). Catalase activity ranged from $7.483 \pm 0.187 \mathrm{mU} / \mathrm{mL}$ to $8,080 \pm 0,661 \mathrm{mU} / \mathrm{mL}$ (Figure 1d).

It is clear from the trend that radical superoxide concentration was increased along with cancer cell number. Meanwhile, there was a very small increase in MnSOD activity and hydrogen concentration along with the increase in cancer cell number. In contrast, there was a small decrease in catalase activity along with the increase in cancer cell number. Observation at 72 hours, a large increase in cancer cell number, but decreased radical superoxide concentration, MnSOD activity, and hydrogen peroxide concentration. The next 24 hours the reverse occurs, the number of cells cancer has decreased while the concentration of supeoxide radicals, MnSOD activity, hydrogen peroxide concentration has increased, while CAT activity has decreased during observation.

In Figure 2 and 3, it can be seen that there is a lot of red light from DHE. The greater the red luminescence indicates the greater concentration of radical superoxides. Based on the results of the Pearson correlation test, it was found that the cancer cell number was influenced by radical superokside concentration $(\mathrm{p}<0.05)$.

\section{Discussion}

Tumour cell produce more ROS than their normal cell, which is involved in the initiation and progression of cancer (Moloney and Cotter, 2017). In this research showed increased radical superoxides along with the length with observation (Figure $2 a$ ). The cell count was shown to decrease at 96 hours observation on the 24-well plate (Figure 1), but if the observation was conducted on the 12-well plate, there was no decrease in the cell count. The observation was continued until up to 120 hours
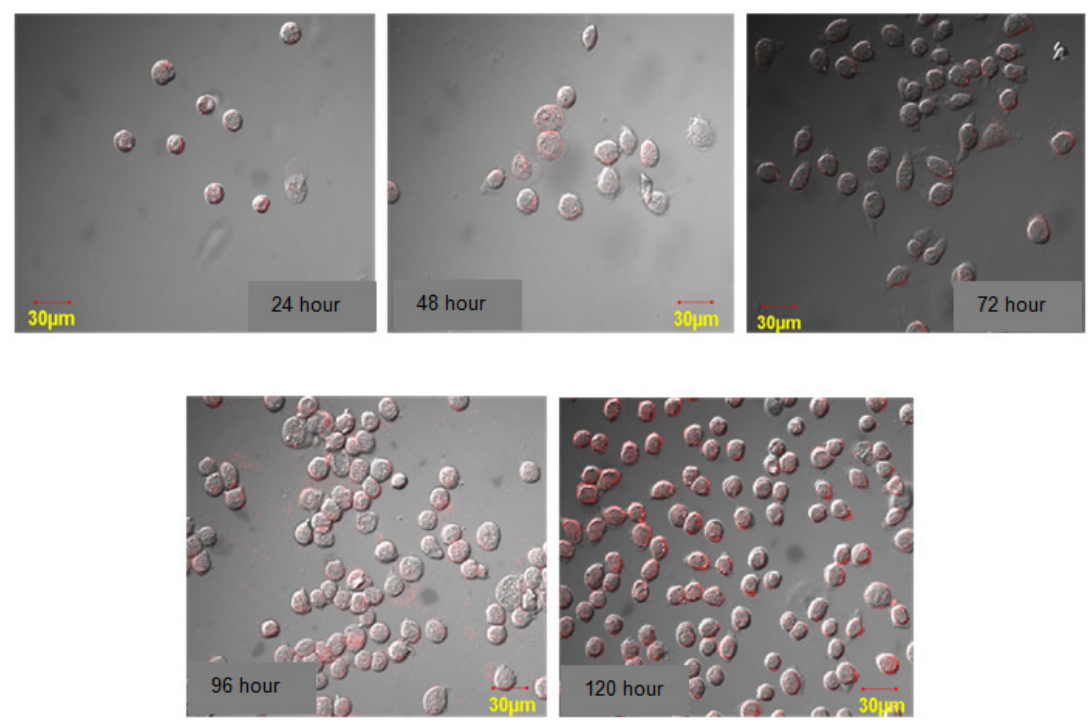

Figure 3. Radical Superoxide of Cell Line MCF-7 with Super Imposed (SI) DHE Staining 
(unpublished data). The size of the well plate would affect the cell growth.

ROS are classified as endogenous carcinogen that induced cell mutation. The balance between the amount of oxidants and antioxidants will affect the cancer cell number. Oxidants will be converted by antioxidants into another oxidant compounds or neutral compounds. Radical superoxides will be converted by MnSOD to hydrogen peroxide, which will then be converted by CAT into water. Hydrogen peroxide will be converted into hydroxyl radicals when there is iron and low concentration of CAT. The hydroxyl radical is more reactive than the other oxidants. This hydroxyl radical will react with fat, resulting in the process of lipid peroxidation it will cause membrane damage (Fang et al., 2009; Deepti et al., 2010; Das et al., 2012, Li et al., 2012; Prasad et al., 2016;)

In the MCF-7 cell line, based on the research by Kattan et al., (2008), there was a lower activity of MnSOD compared to the other breast cancer cell lines. However, in this study there was an increase in MnSOD activity, both convert radical superoxides into hydrogen peroxide. But the CAT activity in this cell line did not change significantly with the increase of time observation. Based on statistical analysis, the compounds that affect the cancer cells number are radical superoxides.

Radical superoxide is one of the ROS. ROS can increase proliferation, inhibit proliferation, or cell apoptosis, depending on its level. The increase in cell number is due to an increase in cell proliferation. Cell proliferation occurs through the Akt pathway. ROS may inhibit PTEN resulting in a continuous cycle of the cell path despite mutations or damage to the produced cells (Kresno, 2011; Prasad et al., 2016).

The decrease in cell number is due to inhibition of proliferation and/or increased apoptosis. The cause of inhibition of proliferation and increased apoptosis are probably due to the increased concentration of radical superoxides and hydrogen peroxide. This increase leads to an increase in oxidative stress that induces AP1, which in turn induces p53 that triggers the release of cytochrome $\mathrm{c}$ from the mitochondria to the cytosol. Cytochrome $\mathrm{c}$ cytosol can bind to Apaf 1 and activates caspase 9 in apoptosome, which is a response to various triggers in cell death. In addition, p53 phosphorylation will also induce p21 that will inhibit cellular cycles, resulting in inhibition of cell proliferation (French et al., 2008; Gupte and Mumper, 2009, Moloney and Cotter, 2017).

In conclusion, the increase in cancer cell number is influenced by radical superoxide

\section{Conflict of interest}

The authors have no conflict of interest.

\section{Acknowledgements}

We would like to extend our gratitude to the Faculty of Medicine, Lambung Mangkurat University and the Ministry of Research, Technology and Higher Education for the scholarships awarded.

\section{References}

Atala E, Fuentes J, Wehrhahn MJ, Speisky H (2017). Quercetin and related flavonoids conserve their antioxidant properties despite undergoing chemical or enzymatic oxidation. Food Chem, doi: http://dx.doi.org/10.1016/j. foodchem.2017.05.023

Chio IIC, Tuveson DA (2017). ROS in cancer : The burning question. Trends Mol Med, 23, 411 - 29

Das A, Bhavani G, Oliver HV, Andrea ID, Frederick AV (2012). Inhibition of ROS-induced apoptosis in endothelial cells by nitrone spin traps via induction of Phase II enzymes and Supression of Mitochondria-dependent pro-apoptotic signaling. Biochem Pharmacol, 84, 486 - 97.

Deepti SV, Brian KR, Periannan K ( 2010). In vivo imaging of free radicals and oxygen. In free radicals and antioxidant protocols. Second Edition. Edited by RaoM. Uppu Southern University and A and M College, Baton Rouge, LA, USA, 3-27.

Fang J, Takahiro S, Hiroshi M (2009). Therapeutic strategies by modulating oxygen stress in cancer and inflammation. Adv Drug Deliv Rev, 61, 290-302.

French JP, Hamilton KL, Quindry JC, et al (2008). Exerciseinduced protection against myocardial apoptosis and necrosis: MnSOD, calcium handling protein and calpain. FASEB J, 22, $2862-71$.

Gupte A, Mumper RJ (2009). Elevated copper and oxidative stress in cancer cells as a target for cancer treatment. Cancer Treat Rev, 35, 32- 46.

Kattan Z, Minig V, Leroy P, Dauça M, Becuwe P (2008). Role of manganese superoxide dismutase on growth and invasive properties of human estrogen-independent breast cancer cells. Breast Cancer Res Treat, 108, 203-15.

Kresno SB (2011). Basic science oncology. Second edition. Faculty of Medicine UI. Jakarta, 25 - 35.

Li L, Ganchimeg I, Spencer BG (2012). Reactive oxygen species regulation of autophagy in cancer: Implications for cancer treatment. Free Radic Biol Med, 53, 1399-1410

Moloney JN, Cotter TG (2017). ROS signalling in the biology and cancer. Semin Cell Dev Biol, https://doi.org/10.1016/j. semcdb.2017.05.023

Prasad S, Gupta SC, Tyag AK (2016). Reactive oxygen species (ROS) and cancer: Role of antioxidative nutraceuticals. Cancer Lett, 387, 95-105.

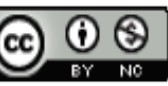

This work is licensed under a Creative Commons AttributionNon Commercial 4.0 International License. 